\title{
COMPETITION AMONG LATE-SUCCESSIONAL TREE SPECIES ACROSS \\ DIFFERENT TOPOGRAPHIC POSITIONS OF A SRI LANKAN RAIN FOREST.
}

\author{
B M P Singhakumara, E P S K Ediriweera and P M S Ashton \\ Department of Forestry and Environmental Science \\ University of Sir Jayewardenepura
}

The plant height growth, canopy expansion and foliar nutrients allocations provide the evidence to understand competitive role by canopy species in part of light and soil moisture gradient. Experiments were designed to investigate competitive outcomes of nine late-succesional tree seedlings in different light and soil moisture regimes. Tree species were planted in the canopy gap and forest understory in different topographic positions; valley, midslope and ridgetop. At the end of every year height, root collar diameter, leaf number and mortality were recorded. Results showed that Shorea trapezifolia and Syzygium rubicundum can be regarded as the most light demanding species with competitive superiors as judged from its height increment, leaf and branches increments with crown structure, root collar diameter and leaf nutrients allocating pattern. At other extremes are Mesua ferrea and Shorea worthingtonii, most which are the most, shade tolerant and with lower competitive ability in this group. Patterns in competitive hierarchy among late successional canopy species strongly support site specialisation and establishment of regeneration.

Proceedings of the Ninth Annual Forestry and Environment Symposium 2003 of the Department of Forestry and Environmental Science, University of Sri Jayewardenepura, Sri Lanka 